\begin{tabular}{|c|c|c|}
\hline \multicolumn{3}{|c|}{ Jurnal Warna : Jurnal Pendidikan Dan Pembelajaran Anak Usia dini. } \\
& Maret 2020. Vol 05. No. 01 \\
\hline Received: Maret 2020 & Accepted: Maret 2020 & Published: Maret 2020 \\
\hline & Article DOI: 10.24903/jw.v5i2.427 \\
\hline
\end{tabular}

\title{
PERMAINAN FINGER PAINTING UNTUK PENGEMBANGAN KEMAMPUAN MOTORIK HALUS ANAK USIA DINI
}

\author{
Maria Evivani \\ PG-PAUD, FKIP, Universitas Lampung, \\ maria.evivani4025@students.unila.ac.id \\ Renti Oktaria \\ PG-PAUD, FKIP, Universitas Lampung, \\ renti.oktaria@fkip.unila.ac.id
}

\begin{abstract}
ABSTRAK
Artikel ini sebagai kajian pustaka yang bertujuan untuk dapat mengetahui seberapa penting penerapan yang dilakukan melalui permainan finger painting dalam pengembangan kemampuan motorik halus anak yang menggunakan jari-jemari tangan dan gerakan pergelangan tangan yang sesuai dengan Standar Pencapaian Perkembangan Anak (STPPA) yang termuat di dalam Peraturan Menteri pendidikan dan Kebudayaan (PERMENDIKBUD) Nomor 137 Tahun 2014 Tentang Standar Nasional Pendidikan Anak usia Dini. Kemampuan motorik halus pada permainan ini akan melibatkan perkembangan otot-otot kecil khususnya pada bagian tangan anak. Maka dari itu penerapan permainan finger painting ini diharapkan dapat sesuai dalam pencapaian perkembangan motorik halus anak dan permainan ini tidak menyimpang dari hakikat anak yaitu belajar melalui bermain yang secara tidak langsung akan mengembangan motorik halus anak yang tertuang dalam STPPA terkait gerakan tangan yaitu mengkoordinasikan tangan dan mata untuk melakukan gerakan rumit, melakukan gerakan manipulatif untuk menghasilkan suatu bentuk dengan berbagai media, dan mengekspresikan diri dengan berkarya seni menggunakan berbagai media.
\end{abstract}

Kata kunci: finger painting, motorik halus, anak usia dini

\section{ABSTRACT}

This article is a literature review that aims to find out how important the application is through finger painting in developing the fine motor skills of children who use their fingers and wrist movements in accordance with the Child Development Achievement Standards (STPPA) contained in the Regulation Minister of Education and Culture (PERMENDIKBUD) Number 137 of 2014 concerning National Standards for Early Childhood Education. Fine motor skills in this game will involve the development of small muscles, especially in the child's hand. Therefore the application of the finger painting game is expected to be suitable in achieving the fine motor development of children and this game does not deviate from the nature of the child namely learning through play which will indirectly develop the fine motor skills of the child contained in the STPPA related to hand movements namely coordinating the hands and eyes to make complicated movements, manipulative movements to produce a form with various media, and express themselves by creating art using various media.

Keywords: finger painting, fine motor skills, early childhood 


\begin{tabular}{|l|c|c|}
\hline \multicolumn{3}{|c|}{ Jurnal Warna : Jurnal Pendidikan Dan Pembelajaran Anak Usia dini. } \\
Maret 2020. Vol 05. No. 01 \\
\hline Received: Maret 2020 & Accepted: Maret 2020 & Published: Maret 2020 \\
\hline & Article DOI: $10.24903 /$ jw.v5i2.427 \\
\hline
\end{tabular}

\section{PENDAHULUAN}

Pengertian PAUD menurut UndangUndang No. 20 Tahun 2003 tentang Sistem Pendidikan Nasional pasal 1 ayat 14 menyatakan bahwa: Pendidikan anak usia dini (PAUD) adalah suatu upaya pembinaan yang ditujukan pada anak sejak lahir sampai dengan usia enam tahun yang dilakukan melalui pemberian rangsangan pendidikan untuk membantu pertumbuhan dan perkembangan jasmani dan rohani agar anak memiliki kesiapan dalam memasuki pendidikan lebih lanjut. Salah satu pedoman guru untuk mengembangkan dan mengoptimalkan aspek perkembangan dan pertumbuhan anak usia dini ialah PERMENDIKBUD Nomor 137 Tahun 2014. Di dalamnya tertuang semua aspek perkembangan yang perlu dikembangkan, ada 6 aspek yaitu: nilai agama dan moral; fisikmotorik; kognitif; bahasa; sosial-emosional; dan seni. Aspek perkembangan tersebut harus dikembangkan agar anak dapat mencapai perkembangan yang optimal. Berdasarkan Peraturan Mentri Pendidikan dan Kebudayaan Republik Indonesia Nomor 137 Tahun 2014 tentang Standar Nasional Pendidikan Anak Usia Dini Bab IV Pasal 10 butir ke 3 : "Fisik motorik meliputi: a) motorik kasar, mencakup kemampuan gerakan tubuh secara terkoordinasi, lentur, seimbang, lincah, lokomontor, non-lokomotor, dan mengikuti aturan; b) motorik halus, mencakup kemampuan dan kelenturan menggunakan jari dan alat untuk mengeksplorasi dan mengekspresikan diri dalam berbagai bentuk; c) kesehatan dan perilaku, mencakup berat badan, tinggi badan, lingkar kepala sesuai usia serta kemampuan berperilaku hidup bersih, sehat, dan peduli terhadap keselamatanya."

Anak usia dini memerlukan salah satunya perkembangan motorik ini guna untuk kesiapan mereka dalam melanjutkan pendidikannya yang lebih tinggi. Misal untuk menulis, melatih keseimbangan tubuhnya, dan lain-lain. Karena masa usia dini merupakan masa dimana kepesatan dalam pertumbuhan dan perkembangannya sangat tinggi, maka dari itu masa ini lah anak dapat dilatih supaya perkembangnya khususnya motorik dapat optimalkan, ini harus diusahakan supaya perkembangan nya tidak terlewati begitu saja.

Pengembangan motorik perlu dilatih sejak dini, misalnya dengan permainan finger painting ini, permainan tersebut dapat melatih motorik halus terkhusus jari-jemari tangan dan gerakan pergelangan tangan. Dan disini anak dapat mengekspresikan kesukaannya baik dari segi warna, bentuk, maupun tekstur.

\section{METODE PENELITIAN}

Pendekatan yang digunakan menggunakan metode deskriptif melalui kajian pustaka yang ada disekitar. Mengumpulkan informasi mengenai berbagai pengertian dan karakteristik dari kata kunci yang dibutuhkan dan teori pendukung guna melengkapi data yang ada. 


\begin{tabular}{|l|c|c|}
\hline \multicolumn{3}{|c|}{ Jurnal Warna : Jurnal Pendidikan Dan Pembelajaran Anak Usia dini. } \\
Maret 2020. Vol 05. No. 01 \\
\hline Received: Maret 2020 & Accepted: Maret 2020 & Published: Maret 2020 \\
\hline & Article DOI: $10.24903 /$ jw.v5i2.427 \\
\hline
\end{tabular}

Untuk memperjelas penelitianini dilengkapi juga dengan hasil penelitianpenelitian yang terdahulu.

\section{HASIL DAN PEMBAHASAN}

\section{Anak Usia Dini}

Anak usia dini menurut Fadillilah di dalam jurnal Handayani (2014:19) ialah "anak yang berkisaran antara usia 0-6 tahun, yang memiliki pertumbuhan dan perkembangan yang luar biasa sehingga memunculkan berbagai keunikan pada dirinya". Menurut Mutiah (2010:2) anak usia dini ialah anak yang memiliki rentang waktu sejak anak lahir hingga usia 6 tahun, dimana pada rentang usia ini pemberian rangsangan pendidikan untuk membantu pertumbuhan dan perkembangan jasmani maupun rohani, agar anak memiliki kesiapan dalam menempuh pendidikan lebih lanjut." Berdasarkan pengertian ini, anak usia dini ialah individu yang rentang usia 0 sampai 6 tahun, dimana pada masa ini pemberian stimulasi untuk pertumbuhan dan perkembangan individu sangat baik untuk dilakukan supaya semua aspek dapat tercapai sesuai dengan yang diprediksikan.

Anak usia dini akan melanjutkan pendidikannya ke jenjang yang lebih tinggi, maka dari itu anak sebelum ia melanjutkan pendidikannya individu harus dibekali dengan stimulus yang tepat untuk kesiapan anak baik segi fisik maupun psikologisnya. Pada masa inilah yang tepat untuk pemberian bekal tersebut, ini dilakukan supaya perkembangan anak, guna kesiapannya tersebut dapat optimal saat masuk ke jenjang lanjutan yang ia jalani.

Menurut Richard (2005:27) karateristik anak yang khas yaitu: Anak bersifat egosentris, cenderung melihat dan memahami sesuatu dari sudut pandang sendiri; Anak memiliki rasa ingin tahu yang besar, keinginan anak sangat bervariasi karena tergantung dengan apa yang diminati anak; Anak adalah makhluk sosial, anak akan membangun kepuasan melalui penghargaan diri ketika diberi kesempatan untuk bekerjasama dengan temannya; Anak bersifat unik, karena setiap anak memiliki kepribadian yang berbeda-beda; Anak umumnya kaya akan fantasi, dikarenakan imajinasi anak berkembang melebihi apa yang dilihatnya; Anak memiliki daya konsentrasi yang pendek, arena perhatian anak mudah teralihkan; Anak merupakan masa belajar yang paling potensial. Berdasarkan ini ciri khas anak yakni memiliki karkateristik yang beraneka ragam.

Dalam PERMENDIKBUD RI Nomor 137 Tahun 2014 Bab 10 tentang Standar Nasional Pendidikan Anak Usia Dini: Lingkup perkembangan sesuai tingkat usia anak meliputi: Aspek nilai Agama dan Moral, meliputi berprilaku jujur, penolong, sopan, hormat, sportif, menjaga kebersihan diri dan lingkungan, mengetahui hari besar agama, menghormati, dan toleran terhadap agama orang lain; Aspek Fisik Motorik, meliputi motorik kasar, motorik halus, serta kesehatan dan perilaku keselamatan; Aspek Kognitif, meliputi belajar dan pemecahan masalah, 


\begin{tabular}{|l|c|c|}
\hline \multicolumn{3}{|c|}{ Jurnal Warna : Jurnal Pendidikan Dan Pembelajaran Anak Usia dini. } \\
Maret 2020. Vol 05. No. 01 \\
\hline Received: Maret 2020 & Accepted: Maret 2020 & Published: Maret 2020 \\
\hline & Article DOI: $10.24903 /$ jw.v5i2.427 \\
\hline
\end{tabular}

berfikir logis, dan berfikir simbolik; Aspek Bahasa, meliputi memahami bahasa reseptif, mengekspresikan bahasa, dan keaksaraan; Aspek Sosial-Emosional, meliputi kesadran diri, rasa tanggung jawab untuk diri dan orang lain, dan perilaku prososial; Aspek Seni, meliputi kemampuan, mengeksplorasi, dan mengekspresikan diri, berimajinasi dengan gerakan, musik, drama, dan beragam bidang seni lainnya (seni lukis, seni rupa, kerajinan), serta mampu mengapresiasi karya seni, gerak dan tari, serta drama. Yang perlu dikembangkan dan distimulasi pada anak usia dini ada 6 aspek, dan artikel ini akan membahas mengenai fisik motorik anak

\section{Motorik Halus}

Tubuh manusia memiliki komponen motorik yang tidak terpisahkan, guna membantu syaraf untuk menggerakkan tubuh.

Dalam Depdiknas menuliskan bahwa "motorik halus ialah gerakan yang melibatkan bagian-bagian tubuh tertentu yang dilakukan oleh otot-otot kecil serta memerlukaan koordinasi yang cermat, seperti menggunting, mengikuti garis, menulis, meremas, menggenggam, menggambar, menyusun balok, memasukkan kelereng ke lubang, membuka dan menutup objek dengan mudah, menuangkan air ke dalam gelas tanpa berceceran, menggunakan kuas, krayon, dan spidol serta melipat".

Perkembangan motorik halus pada anak usia dini difokuskan pada pengordinasian otototot halus anak. Pada hal ini berkaitan dengan gerakan tangan, dalam PERMENDIKBUD NOMOR 137 TAHUN 2014 Tentang Standar
Tingkat Pencapaian Perkembangan Anak: "Pada usia 4-5 tahun koordinasi gerakan tangan yang menggunakan motorik halus anak berkembang dengan pesat, seperti anak bisa membuat garis vertikal,-horizontal, lengkung kiri dan kanan, menjiplak bentuk, mengontrol gerakan tangan yang menggunakan otot halus (menjumput ataupun memilin), mengkoordinasikan tangan dan mata untuk melakukan gerakan rumit, melakukan gerakan manipulatif untuk menghasilkan suatu bentuk dengan berbagai media, mengekspresikan diri dengan berkarya seni menggunakan berbagai media."

Perkembangan motorik halus anak disebabkan oleh pemberian stimulasi dan faktor pendukung lainnya. Menurut Rahyubi (2014: 225) faktor yang mempengaruhi perkembangan motorik yakni: (1) perkembangan sistem syaraf (2) kondisi fisik (3) motivasi yang kuat (4) lingkungan yang kondusif (5) aspek psikologis (6) usia (7) jenis kelamin (8) bakat dan potensi. Faktor yang mempengaruhi perkembangan motorik halus anak tidak hanya karena memiliki kondisi fisik yang sempurna tetapi juga harus ada bakat dan potensi yang dimiliki sehingga dapat distimulus dengan berbagai permainan. Kondisi psikologis juga berperan penting dengan diberikan kesempatan dalam berekspresi, lingkungan yang mendukung, serta sarana dan prasarana yang mendukung perkembangan motorik halus anak.

Dalam Hurlock yang diterjemahkan oleh Tjandrasa dan Zarkasih (2002:151), menyatakan bahwa prinsip perkembangan motorik sebagai berikut : a) Perkembangan 


\begin{tabular}{|l|c|c|}
\hline \multicolumn{3}{|c|}{ Jurnal Warna : Jurnal Pendidikan Dan Pembelajaran Anak Usia dini. } \\
Maret 2020. Vol 05. No. 01 \\
\hline Received: Maret 2020 & Accepted: Maret 2020 & Published: Maret 2020 \\
\hline & Article DOI: $10.24903 /$ jw.v5i2.427 \\
\hline
\end{tabular}

motorik bergantung pada perkembangan otot dan syaraf. Perkembangan motorik sejalan dengan perkembangan system syaraf, karena pusat syaraf yang berada di otak ataupun yang berada di tulang belakang berkembang sejak saat lahir. Pusat syaraf yang yang berada di tulang belakang berkembang lebih baik dibanding pusat syaraf yang berada di otak, maka dari itu gerakan reflek pada saat anak lahir lebih baik dikembangkan dengan sengaja ketimbang berkembang dengan sendiri. b) Belajar keterampilan motorik tidak terjadi sebelum anak matang, sebelum sistem syaraf dan otot berkembang dengan baik dikembangkan dengan sengaja ketimbangkan berkembang dengan sendiri. c) Perkembangan motorik mengikuti pola yang akan diramalkan. Motorik pada anak mulai berkembang dapat terlihat dari adanya perubahan gerakan yang dilakukan anak. Seiring matangnya syaraf anak, kegiatan yang melibatkan motorik kasar perlahan - lahan anak melakukan gerakan yang sifat gerakannya hanya melibatkan motorik (otot) dan anggota tubuh yang benar. Berdasarkan penjabaran ini dapat disimpulkan bahwa standar - standar yang ada di PERMENDIKBUD harus dipenuhi, agar keterlambatan dalam pertumbuhan dan perkembangan pada fisik anak terutama bagian tangan tidak terjadi. Oleh karenanya, semua keterampilan tersebut harus dipelajari sejak dini supaya kematangan motorik, dapat berkembang secara optimal, dan sesuai dengan standar yang dicanangkan, tetapi juga harus memperhatikan kondisi fisik anak karena faktor internal juga sangat mempengaruhi perkembangan motorik dan fungsi syaraf pada anak.

\section{Finger Painting}

Menurut Montolalu di dalam jurnal Fitria (2004) pembelajaran melukis menggunakan jari atau finger painting memiliki tujuan yaitu mengekspresikan kesenangannya melalui media lukis dengan menggunakan bagian telapak dan jari-jemari tangan untuk melatih otot-otot tangan dan jari, koordinasi matatangan, melatih kecakapan mengkombinasikan warna, memupuk perasaan terhadap gerakan tangan. Menurut Sumanto (2005: 53) menjelaskan bahwa: "finger painting adalah jenis kegiatan membuat gambar yang dilakukan dengan cara menggoreskan adonan warna (bubur warna) secara langsung dengan jari tangan secara bebas di bidang gambar, batasan jari disini adaalah semua jari tangan, telapak tangan, sampai perkgelangan tangan". tangan, sampai perkgelangan taangan.

Berdasarkan uraian ini finger painting ialah salah satu kegiatan yang melibatkan kemampuan motorik jari hingga pergelangan tangan anak, yang berarti dalam kegiatan ini secara tidak langsung melatih motorik halus pada bagian tangan yang dilibatkan. Hal ini juga dapat memberikan kesenangan pada anak karena jari hingga pergelangan tangan anak bersentuhan langsung pada objek (bahan dan alat) yang digunakan pada kegiatan ini.

Alat dan bahan untuk bermain anak sebaiknya mengguankan objek yang aman supaya tidak melukai bagian tubuh anak. Alat dan bahan yang digunakan dalam permainan finger painting ini mudah untuk ditemukan, 


\begin{tabular}{|l|c|c|}
\hline \multicolumn{3}{|c|}{ Jurnal Warna : Jurnal Pendidikan Dan Pembelajaran Anak Usia dini. } \\
Maret 2020. Vol 05. No. 01 \\
\hline Received: Maret 2020 & Accepted: Maret 2020 & Published: Maret 2020 \\
\hline & Article DOI: $10.24903 /$ jw.v5i2.427 \\
\hline
\end{tabular}

dan aman bagi anak Menurut Montalalu (2009: 3.17) alat dan bahan yang digunakan untuk bermain finger painting yakni plastik untuk alas, kertas putih, cat dengan 4-8 warna, celemek serta tepung kanji.

Bermain memiliki manfaat, yang paling utama yaitu memberikan kesenangan dan pengetahuan baru dari permainan yang telah dimainkan.

Manfaat dari bermain finger painting diungkapkan oleh Montalalu yaitu: Mengembangkan fantasi, imajinasi, dan kreasi; Mengembangkan ekspresi melalui media lukis dengan gerakan tangan; Melatih otot-otot tangan/jari, koordinasi otot dan mata; Melatih kecakapan dan mengkombinasikan warna; Memupuk perasaan terhadap gerakan tangan; dan Memupuk perasaan keindahan.

\section{Bermain bagi Anak Usia Dini}

Bermain bagi anak merupakan kegiatan yang dibutuhan dan diinginkan oleh anak. Dalam pengamatan Montalalu (2009: 1.3) menyatakan bahwa: Anak memperoleh kesempatan mengembangkan potensi-potensi yang ada apanya; Anak akan menemukan dirinya, yaitu kekuatan dan kelemahannya, kemampuannya serta juga minat dan kebutuhannya; Memberikan peluang bagi anak untuk berkembang seutuhnya, baik fisik, intelektual, bahasa, dan perilaku (psikososial serta emosional); Anak terbiasa menggunakan seluruh aspek pancaindranya sehingga terlatih dengan baik; Secara alamiah memotivasi anak untuk mengetahui sesuatu lebih mendalam lagi." Teori ini menjelaskan bahwa setiap kegiatan bermain yang dilakukan, akan meningkatkan perkembangan anak.

Jenis-jenis bermain yang diungkapkan oleh Smilansky dalam Fauziah (2010: 111) terdiri dari tiga jenis. Berikut penjelasan mengenai tiga jenis main yakni : a) Bermain Simbolik jenis bermain ini berkaitan dengan pemainan konstruktif dan bermain drama dengan menghadirkan sesuatu sebagai simbolik. b) Bermain konstruktif yakni anak menciptakan sendiri atau membangun sendiri pengetahuan yang anak miliki dan menghadirkannya sebagai objek konkrit. Main pembangunan ini memberikan kesempatan untuk anak untuk menghasilkan karya dari gagasan, pemikiran, dan imajinasinya. c) Bermain drama yakni jenis bermain yang memberikan kesempataan kepada anak untuk menciptakan sendiri tokoh imajinasi yang mereka inginkan.

Jenis bermain yang dijelaskan diatas dapat diimplementasikan pada anak melalui permainan. Permainan yang diberikan pada anak, bisa mencangkup seluruh jenis bermain maupun salah satunya, ini disesuaikan dengan kebutuhan anak.

Media ialah alat atau objek penunjang dalam kegiatan main, melalui objek yang ada anak dapat mengekspresikan ataupun bereksplorasi dengan menggabungankan pengetahuan yang anak sudah mengerti terlebih dahulu melalui media yang anak pakai.

Jenis media dalam bermain konstruktif terdiri dari media yang bersifat cair dan terstruktur. 


\begin{tabular}{|l|c|c|}
\hline \multicolumn{3}{|c|}{ Jurnal Warna : Jurnal Pendidikan Dan Pembelajaran Anak Usia dini. } \\
Maret 2020. Vol 05. No. 01 \\
\hline Received: Maret 2020 & Accepted: Maret 2020 & Published: Maret 2020 \\
\hline & Article DOI: $10.24903 /$ jw.v5i2.427 \\
\hline
\end{tabular}

Dalam artikel ini hal yang kita bahas ialah finger painting dimana ini termasuk kedalam bermain konstruktif, dimana anak yang membuat sendiri gambar sesuai keinginannya atau sering disebut menciptakan hasil karyanya sendiri.

Latif (2014: 219) mengungkapkan pengertian dari jenis media bermain konstruktif yaitu: 1) Media yang bersifat cair adalah media yang penggunaan dan bentuknya ditentukan oleh anak, seperti: cat, krayon, spidol, play dough, pasir, air. 2) Media terstruktur mempunyai bentuk yang telah ditetapkan sebelumnya dan mengarahkan bagaimana anak meletakkan bahan-bahan tersebut bersama menjadi sebuah karya, contohnya: balok, lego.

Dalam bermain konstruktif memiliki beberapa manfaat. Menurut Piaget dalam Latif (2014: 220) manfaat bermain konstruktif yaitu : Dapat meningkatkan rasa percaya diri; Mengembangkan koordinasi motorik halusnya; Secara kognisi bergerak mendekati pendekatan operasional konkret, hasil karya anak semakin nyata; Kemampuan berkomunikasi; Keterampilan dengan teman sebaya.

\section{Permainan Finger Painting Terhadap Perkembangan Motorik Halus Anak}

Menurut penelitian yang dilakukan Fitria hasil analisis data dan pembahasan dalam penelitiannya yaitu: 1.) Kemampuan motorik halus anak usia 4-5 tahun sebelum diberikan perlakuan berupa kegiatan finger painting tergolong rendah artinya secara umum perlu dilakukan tindakan finger painting. 2.) Kemampuan motorik halus anak usia 4-5 tahun setelah diberikan perlakuan berupa kegiatan finger painting mengalami peningkatan dan tergolong tinggi artinya terdapat pengaruh setelah diberi penerapan kegiatan finger painting 3.) Kegiatan finger painting memiliki pengaruh yang signifikan terhadap kemampuan motorik halus anak usia 4-5 tahun. Hal ini dapat diketahui bahwa ada perbedaan berupa peningkatan kemampuan motorik halus anak sebelum dan sesudah perlakuan. Kegiatan finger painting memiliki pengaruh sebesar $41,33 \%$ terhadap kemampuan motorik halus anak usia 4-5 tahun.

Menurut penelitian yang dilakukan oleh Nunung, dkk menyatakan bahwa berdasarkan data yang ditelitinya didapatkan hasil uji statistik dengan menggunakan Wilcoxon bahwa positive ranks berjumlah 23 yang berarti terjadi peningkatan pada 23 responden, ties berjumlah 2 yang berarti tidak ada peningkatan pada 2 responden dikarenakan saat kegiatan pre-test hingga post-test responden terlihat malu-malu dan kurang aktif sehingga tidak dapat memaksimalkan kemampuannya saat kegiatan post test, dan nilai $p$ Value adalah $0,001(\alpha<$ $0,05)$, dapat disimpulkan bahwa ada perbedaan yang signifikan perkembangan motorik anak usia pra sekolah sebelum dan setelah diberikan kegiatan finger painting. Hal ini berarti bahwa analisis hipotesis (Ha) diterima yang artinya ada pengaruh kegiatan finger painting terhadap perkembangan motorik halus anak usia pra sekolah.

Menurut penelitian yang dilakukan oleh Immas dan Sri hasil analisis data dan pembahasan dalam penelitiannya yaitu 


\begin{tabular}{|l|c|c|}
\hline \multicolumn{3}{|c|}{ Jurnal Warna : Jurnal Pendidikan Dan Pembelajaran Anak Usia dini. } \\
Maret 2020. Vol 05. No. 01 \\
\hline Received: Maret 2020 & Accepted: Maret 2020 & Published: Maret 2020 \\
\hline & Article DOI: $10.24903 /$ jw.v5i2.427 \\
\hline
\end{tabular}

Penentuan Thitung yaitu diambil dari jumlah jenjang yang kecil tanpa memperhatikan Ttabel yaitu menentukan $(\mathrm{n}, \mathrm{a})$, dimana $\mathrm{n}=$ jumlah sampel dan $\mathrm{a}=$ taraf signifikan 5\% sehingga Ttabel diperoleh dari tabel nilai kritis dalam test Wilcoxon adalah 66. Mengetahui jumlah angka yang diperoleh dari Ttabel berjumlah 66 berarti Thitung $<$ Ttabel $(0,66)$. Thitung $<$ Ttabel berarti Ho di tolak dan Ha diterima. Dari penelitian diatas Thitung $<$ Ttabel yaitu $0<66$, maka hipotesis terhadap penelitian diterima yaitu terdapat pengaruh kegiatan seni finger painting terhadap kemampuan motorik halus anak.

Penelitian-penelitian diatas sangatlah berbanding lurus dengan manfaat dari permainan finger painting menurut Montalalu (2009: 17) yang menyebutkaan bahwa: "Manfaat kegiatan finger painting yaitu dapat mengembangkan ekspresi melalui media lukis dengan gerakan tangan, mengembangkan fantasi, imajinasi, dan kreasi, melatih otot-otot tangan/jari, koordinasi otot dan mata, melatih kecakapan, mengombinasikan warna, memupuk perasaan terhadap gerakan tangan dan memupuk keindahan.”

Dari paparan diatas permainan finger painting dapat mengembangan motorik halus pada tangan anak dan tidak menyimpang dari hakikat anak yakni bermain karena permainan ini dikategorikan bermain konstruktif.

\section{PENUTUP}

\section{Kesimpulan}

Individu yang rentang usianya 0-6 tahun inilah yang disebut dengan anak usia dini. Pada usia ini perkembangan anak yaitu aspek moral agama, fisik motorik, kognitif, bahasa, sosialemosional, dan seni berkembang sangat pesat, dan jika distimulus dengan baik maka perkembangannya dapat optimal dengan baik pula. Perkembangan motorik halus anak terutama pada tangan harus distimulus dengan baik guna optimalisasi otot - otot halus yang ada didalamnya, ini dilakukan supaya pada saat melanjutkan ke jenjang yang lebih tinggi dapat melakukan yang seharusnya anak bisa lakukan.

Menggunakan permainan finger painting dalam kegiatan pembelajaran, anak dapat terlatih dalam mengembangkan motorik halusnya khususnya tangan/jari karena telah terbukti dengan penelitian-penelitian sebelumnya da nada teori yang mendukungnya serta permainan ini tidak menyimpang dari hakikat anak yaitu bermain dan sesuai dengan STPPA yang termuat dalam PERMENDIKBUD Nomor 137 Tahun 2014.

\section{Saran}

Berdasarkan kesimpulan di atas, diharapkan lembaga PAUD dapat memberikan permainan finger painting sebagai permainan wajib dalam mengembangkan kemampuan motorik halus anak. Selain itu, perlu juga diperhatikan bahan-bahan dasar dalam kegiatan bermain finger painting juga harus aman bagi anak. Variasi bahan tambahan lainnya untuk mendukung permainan finger painting juga dapat diperkaya agar anak bisa mendapatkan aneka ragam cara bermain finger painting yang menyenangkan bagi anak usia dini. 


\begin{tabular}{|l|c|c|}
\hline \multicolumn{3}{|c|}{ Jurnal Warna : Jurnal Pendidikan Dan Pembelajaran Anak Usia dini. } \\
Maret 2020. Vol 05. No. 01 \\
\hline Received: Maret 2020 & Accepted: Maret 2020 & Published: Maret 2020 \\
\hline & Article DOI: $10.24903 /$ jw.v5i2.427 \\
\hline
\end{tabular}

\section{DAFTAR PUSTAKA}

Departemen Pendidikan Nasional. 2007. Pengembangan Fisik Motorik di Taman Kanak- Kanak. Jakarta: Dirjen Manajemen Pendidikan Dasar dan Menengah

Fauziah, D.U. 2010. Keindahan Belajar Dalam Prespektif Pedagogi. Jakarta: PT. Unggul Permana Selaras

Fitria Yanti. Pengaruh Finger Painting Terhadap Kemampuan Motorik Halus Anak Usia 4-5 Tahun Di Paud Afifah Marpoyan Damai Pekanbaru. Universitas Riau. (https://jom.unri.ac.id/index.php/JOMFKIP/ article/view/9128/8794 diakses pada tanggal 10 November 2019 pukul 15.09 )

Handayani, Kadek Sri Wuri,dkk. 2018. Pengaruh Finger Painting Terhadap Kemampuan Motorik Halus Anak Usia Dini Kelompok B2 di TK Ganesha.

Universitas Pendidikan Ganesha Jurusan Pendidikan Guru Pendidikan Anak Usia Dini.

(https://ejournal.undiksha.ac.id/index.php/JJ PAUD/article/download/15237/9300 diakses pada tanggal 10 November 2019 pukul 14.29)

Hurlock, Elisabeth B. 2002. Perkembangan Anak( jilid 2). Jakarta: Erlangga

Latif, M, dkk. 2014. Orientasi Baru Pendidiakn Anak Usia Dini. Jakarta: Kencana

Montalalu, B.E.F. 2009. Bermain dan Permainan. Jakarta:Universitas Terbuka
Mutiah, Diana. 2010. Psikologi Bermain Anak Usia Dini. Jakarta: Kencana Prenada Media Group

Nandari, Immas Prima, Sri Setyowati. Pengaruh Kegiatan Seni Finger Painting TerhadapKemampuan Motorik Halus Anak Kelompok B TK RA As Sa'adah Driyorejo Gresik. Jurnal PAUD Teratai. Volume 06 Nomor 03 Tahun 2017. Universitas Negri Surabaya

(http://jurnalmahasiswa.unesa.ac.id/index.ph p/paud-teratai/article/viewFile/20312/18612 diakses pada tanggal 10 November 2019 pukul 15.01)

Nurjanah, Nunung, dkk. Pengaruh Finger Painting Terhadap Perkembangan Motorik Halus Anak Prasekolah di TK At-Taqwa. Jurnal Keperawatan BSI, Vol. V No. 2 September 2017.

(https://ejournal.bsi.ac.id/ejurnal/index.php/i k/article/view/2628/1782 diakses pada tanggal 10 November 2019 pukul 14.58)

Peraturan Menteri pendidikan dan Kebudayaan (PERMENDIKBUD) Nomor 137 Tahun 2014 Tentang Standar Nasional Pendidikan Anak usia Dini

Rahyubi, Heri. 2014. Teori-Teori Belajar dan Aplikasi Pembelajaran Motorik, Deskripsi, dan Tinjauan Kritis. Bandung: Nusa Media

Richard, Woolfsoon. 2005. Why Do Kids Do That. Jakarta: Erlangga

Sumanto. 2005. Pengembangan Kreativitas Senirupa Anak TK. Jakarta: Depdiknas

Undang-Undang No. 20 Tahun 2003 tentang Sistem Pendidikan Nasional 